\title{
Erratum to: Leisure Time Physical Activity and the Risk of Pre-eclampsia: A Systematic Review
}

\author{
H. T. Wolf $\cdot$ K. M. Owe $\cdot$ M. Juhl $•$ \\ H. K. Hegaard
}

Published online: 16 July 2014

(c) Springer Science+Business Media New York 2014

\section{Matern Child Health J (2014) 18:899-910 \\ DOI 10.1007/s10995-013-1316-8}

Under the section "Confounding" the text "The strategy for selecting covariates was described in only two studies [24,31]." should read correctly as "The strategy for selection covariates was described in eight studies (23-27, 30-32)".

The authors would like to change the text under the section "Validation" to "Only four studies measured LTPA based on validated questions $(23,27,28,31)$. Six studies validated the PE diagnosis: five of them by reviewing the medical records for a confirmation of the diagnosis $(22,23,25,27,32)$.

Under the section "LTPA Before and During Pregnancy", the text "Saftlas et al. [32] calculated the risk of
PE associated with a combined exposure-exercise performed both before and during pregnancy. This study was the only one to investigate this relationship, and no association was found." should now read correctly as "The studies investigating LTPA both before and during pregnancy all calculated the risk of PE associated with the combined exposure-exercise performed both before and during pregnancy $(23,27,30,32)$. Only Sorensen et al. found a decreased risk of PE using this combined exposure (30)."

Under Table 3, the categories for sports and exercises namely none, low, middle, high are now changed to quartiles with the first quartile as reference category. The revised table is presented below.

The online version of the original article can be found under doi:10.1007/s10995-013-1316-8.

H. T. Wolf $(\bowtie)$

Department of Obstetrics and Gynaecology, Copenhagen

University Hospital, Rigshospitalet, Copenhagen, Denmark

e-mail: trapwolf@gmail.com

K. M. Owe

Department of Sports Medicine, Norwegian School of Sport

Sciences, Oslo, Norway

M. Juhl $\cdot$ H. K. Hegaard

Research Unit Women's and Children's Health, The Juliane

Marie Centre for Women, Children and Reproduction,

Copenhagen University Hospital, Rigshospitalet, Section 7821,

2100 Copenhagen, Denmark 


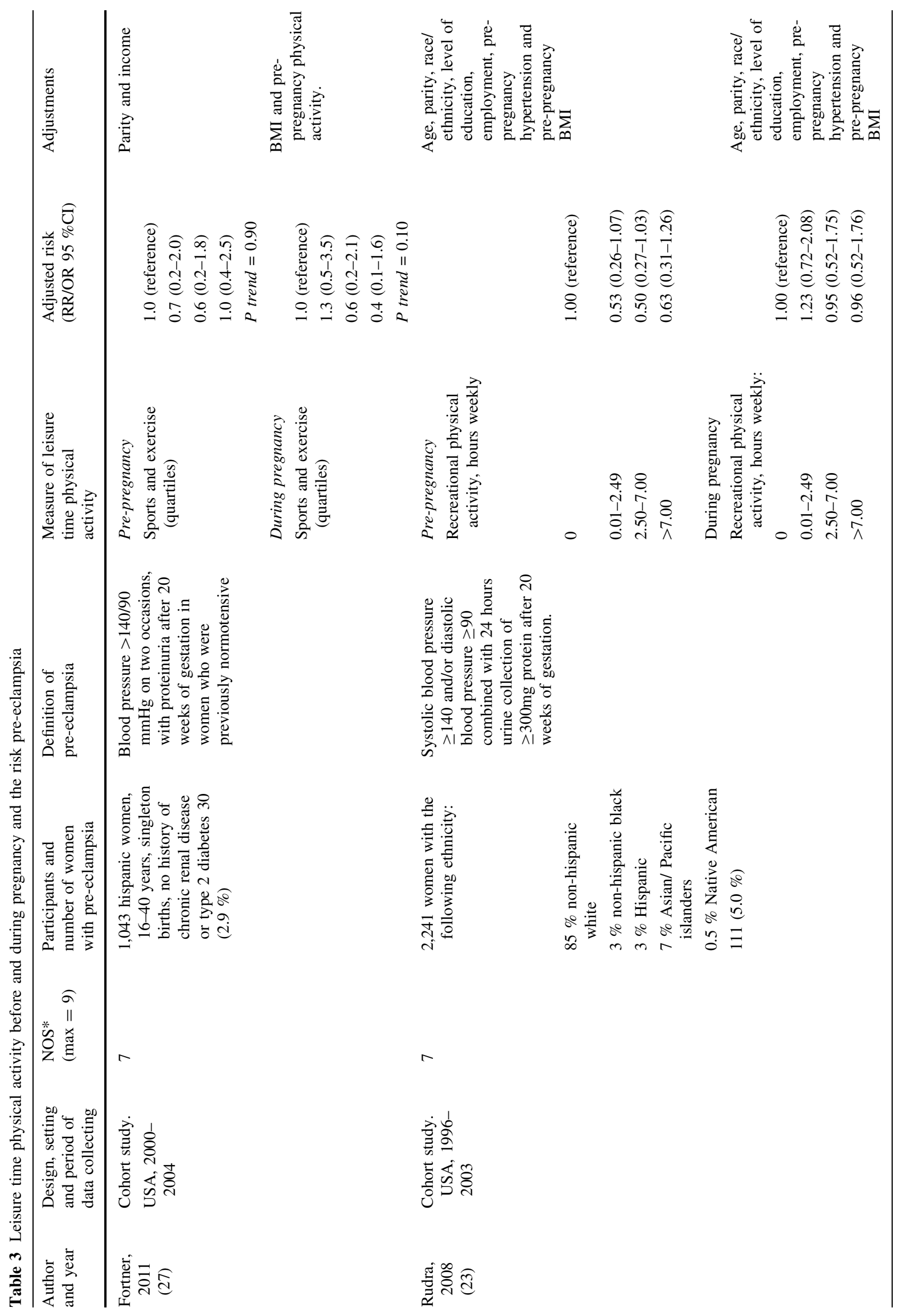




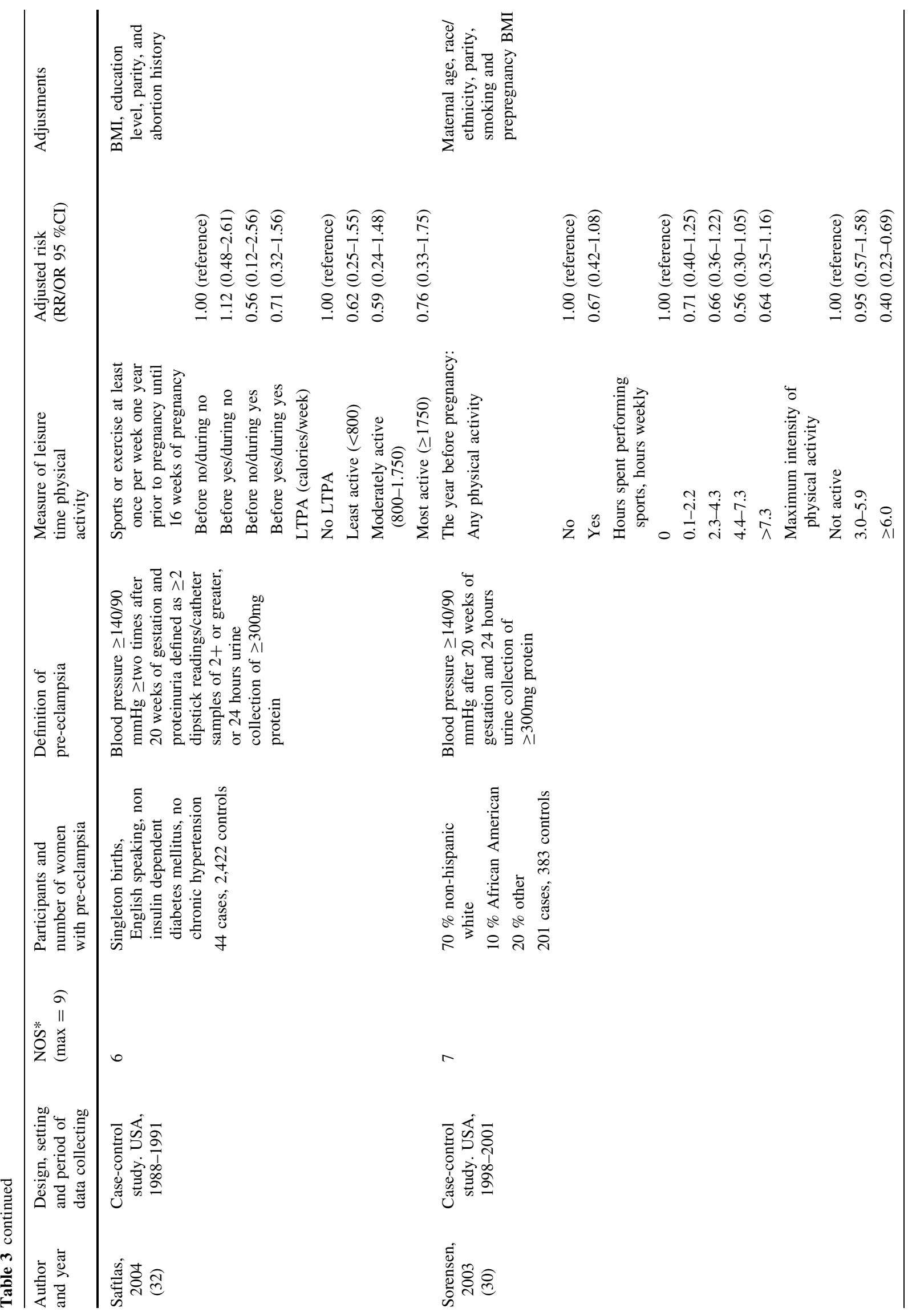




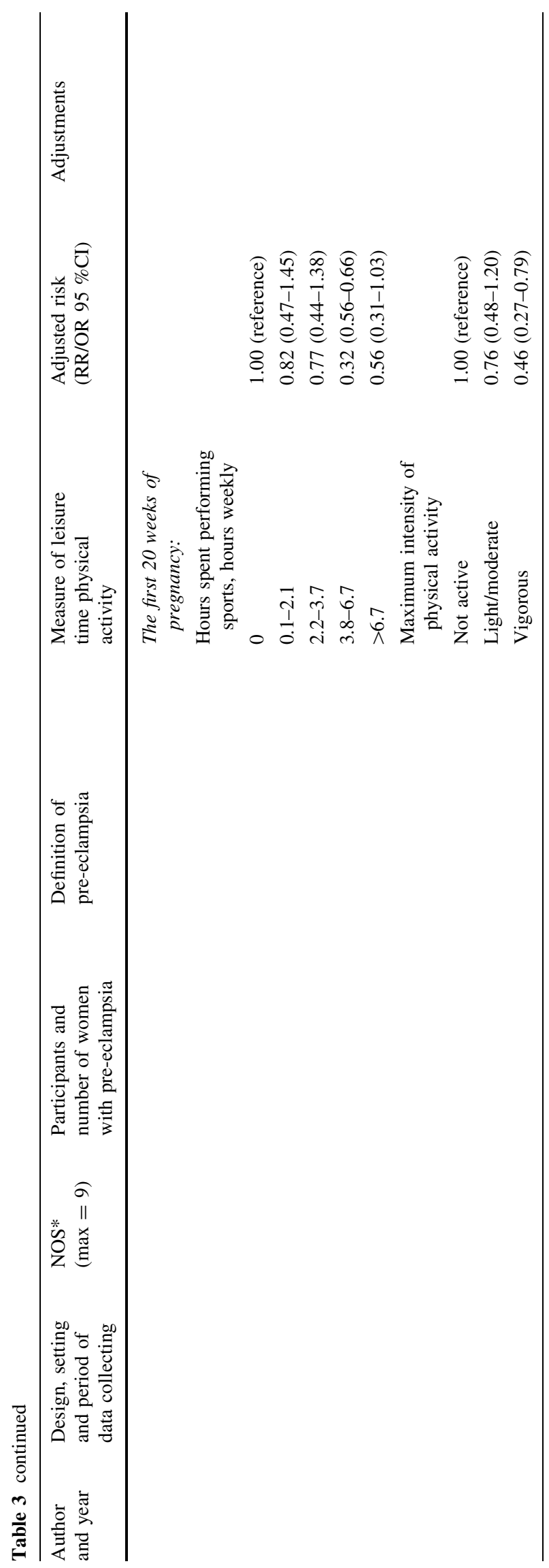

